


\section{Los autores}

\section{Ana Lourdes Álvarez Romero}

Doctora en Humanidades por la Universidad de Sonora y Doctora en Études Romanes por la Université Paul Valéry Montpellier 3. Sus líneas de investigación consisten en el estudio de las relaciones entre los discursos literarios y los antropológicos, la teoría literaria feminista y la literatura mexicana del siglo xx. Sus últimas publicaciones son: "El etnógrafo: autor, mediador y empatía en $\mathrm{La}$ noche de Tlatelolco, Chin chin el teporocho y Vida de Maria Sabina" (Literatura Mexicana, vol. 29, núm.1, 2018, pp. 99-124, ISSN electrónico: 2448-8216); "El testimonio problematizado en Hasta no verte Jesús mío: similitudes y divergencias con Oscar Lewis en la reconstrucción del Otro" en D'oublis et d'abandons. Notes sur l'Amerique Latine (Orbis Tertius, 2017, pp. 59-74, ISBN 978-23678-090-2).

Daniel Avechuco Cabrera

Doctor en Humanidades por la Universidad de Sonora, institución en la que actualmente se desempeña como profesor-investigador. Sus líneas de investigación son: 1) la literatura mexicana, 2) las representaciones culturales de la Revolución mexicana, 3) las relaciones entre la literatura y la violencia, y 4) las relaciones entre la literatura y la imagen. En los últimos años, publicó dos artículos 
ligados a estas líneas: "La Revolución narrada desde los márgenes: representaciones anómicas de la violencia en Cartucho, de Nellie Campobello" (Literatura Mexicana, del Instituto de Investigaciones Filológicas de la UNAM), y "Formas de recordar la guerra: violencia en la fotografía y el cine documental de la Revolución mexicana" (Revista Humanidades, de la Universidad de Costa Rica).

Noé Blancas Blancas

Doctor en Ciencias del Lenguaje por la Benemérita Universidad Autónoma de Puebla (BUAP) y maestro en Letras Mexicanas por la Universidad Nacional Autónoma de México (unAm). Es ProfesorInvestigador en la Universidad Popular Autónoma del Estado de Puebla (upaep). Miembro del Sistema Nacional de Investigadores. Sus líneas de investigación se centran en la Narrativa mexicana del siglo xx: Juan Rulfo, José Revueltas, Agustín Yáñez, y la citación en el relato literario. Ha publicado los libros: La escritura circular y concéntrica en El apando, de José Revueltas (BUAP, 2014) y Pedro Páramo, novela aural (BUAP, 2015). Entre sus artículos, se encuentran: "Estío', la puerta a la transgresión” (Graffylia, núm. 19, 2014); "Sigüenza y Rulfo: marcas orales en la citación”, en Robin Ann Rice (coord.), Arte, cultura y poder en la Nueva España (Madrid: GRISO, 2016); "Recordar Luvina 'como si así fuera", en Francisco Ramírez y Pedro Ángel Palou (eds.), El Llano en llamas, Pedro Páramo y otras obras: en el centenario de su autor (Madrid, Iberoamericana/Frankfurt, Vervuert, 2017); “'Talpa', un discurso confesional”, (Tonos digital, núm. 35, 2018); "Episodio de las hebritas de oro': hilos entre la ronda y el relato" (Hipogrifo. Revista de literatura y cultura del Siglo de Oro, vol. 6, núm. 1, 2018).

Jefferson Eduardo da Paz Barbosa

Doctorando por el Programa de Pós-graduação em Estudos da Linguagem (PPgEL), de la Universidade Federal do Rio Grande do 
Norte (UfRN), maestro en Historia y Crítica de la Metafísica por el Programa de Pós Graduação em Filosofia (PPFGIL-UfrN) y graduado en Letras (UFRN). Es integrante del grupo de investigación ACEfalo (Agenciamento Coletivo de Estudos em Filosofia da Arte e da Literatura) y del grupo Escritor plural: estudos pludisciplinares da obra de Roland Barthes, ambos acreditados por CAPES-CNPq. Estudia las poéticas de la posmodernidad en ss múltiples experimentaciones y sus cercanías con la filosofía, antropología y psicología. Con una especialidad en filosofía francesa contemporánea, publicó los artículos: "A liberdade de uma cabeça cortada: Maurice Blanchot, literatura e revolução"(Mnemosine, Río de Janeiro, vol. 13, 2017, pp. 69-87; "Poesia e dialética da negritude em Aimé Césaire e Jean-Paul Sartre” en Elio Ferreira (org.), Literatura e cultura afrodescendente e indigena: Brasil, Caribe, Colômbia e Estados Unidos (Fundação Universidade Estadual do Piauí, 2017, vol. 5, pp. 179-186). Actualmente desarrolla una investigación sobre el escritor chileno Carlos Lloró.

\section{Manuel Ernesto Parra Aguilar}

Licenciado en Literaturas Hispánicas por la Universidad de Sonora y Maestro en Estudios de Artes y Literatura por la Universidad Autónoma del Estado de Morelos. Ha sido instructor en los talleres de literatura, con especialidad en creación poética, en la Biblioteca Pública Central de Hermosillo; también ha ofrecido charlas del género del poema en prosa y del poema infantil en las ciudades de Hermosillo, Navojoa y Magdalena de Kino, Sonora. Su área de trabajo se centra en la poesía hispanoamericana reciente, con especialidad en el poema en prosa, en donde su proyecto más reciente asociado a esta línea de investigación es "La redención de Fausto, una propuesta de lectura" (2018). Es autor de los libros de poemas Breves (CECAN, 2017), Portuaria (ISC, 2014), Pertenencias (Mantis, 2014), Manual del mecánico (vox, Argentina, 2012), en- 
tre otros. Como creador literario ha merecido el primer lugar del 49 Concurso de cuento breve de la revista Punto de Partida, unam (2018); el Premio Nacional de Poesía de Zaachila, Oaxaca (2017); el Premio Nacional de Cuento de Zaachila, Oaxaca (2017); el XV Premio Nacional de Poesía Amado Nervo (2016); el XII Premio Nacional de Poesía Alonso Vidal (2013); el premio del Concurso del Libro Sonorense, por el ISC (2013); el XIII Premio Nacional de Poesía Tintanueva (2011) y el Premio Internacional de Poesía Oliverio Girondo (2005), organizado por la Sociedad Argentina de Escritores, SADE.

Pablo Nicolás Pachilla

Doctor en Filosofía por la Universidad de Buenos Aires y la Université Paris 8 . Ejerce la docencia en la UBA y la UnSAM. Su tesis doctoral está abocada a la relación entre el idealismo trascendental kantiano y el empirismo trascendental deleuziano. Actualmente es becario posdoctoral de CONICET, donde trabaja sobre la relación entre imaginación, temporalidad y ontología en las lecturas deleuziana y heideggeriana de Kant. Investiga asimismo sobre filosofías contemporáneas de la naturaleza desde un punto de vista posnaturalista. Ha publicado artículos en Areté. Revista de Filosofía, Revue Philosophique de la France et de l'Étranger, Logos: Revista de Lingüistica, Filosofía y Literatura, Boletín de Estética, El Banquete de los Dioses y Philosophia, entre otras revistas, y capítulos en libros como Los caminos cruzados de Spinoza, Fichte y Deleuze (Gaudio, Solé y Ferreyra, 2018), En busca del idealismo. Las transformaciones de un concepto (Solé y Lerussi, 2016) y Los caminos de la imagen. Aproximaciones a la ontología del cine (Gutiérrez, 2016), así como en los cinco volúmenes de la serie Deleuze y las fuentes de su filosofía. Es miembro del Grupo Colaborador de Ideas. Revista de Filosofía Moderna y Contemporánea y del proyecto de investigación UBACYT 
2018: "Los caminos cruzados de la libertad: Spinoza, Deleuze y el primer Hegel de Jena”.

Ángeles Ma. del Rosario Pérez Bernal

Posdoctorado en Literatura y Filosofía. Universidad de París 1, Pantheon Sorbonne. Doctora en Estudios Latinoamericanos por la Universidad Nacional Autónoma de México. Sus líneas de investigación son Literatura y pensamiento crítico; Intertextualidad, Psicoanálisis; Posestructuralismo. Ha publicado los libros: Literatura, Filosofía y Animalidad (Miguel Ángel Porrúa/uaem, 2012), Devenires de la literatura (Eón/UAEM, 2014), Pensar lo politico. Ontología y mundo contemporáneo (Universidad de Murcia/UAEM, 2016), Deleuze, Borges y las paradojas (Gedisa/UAEM, 2017), Escritura y resistencia. Entre Elena Garro, Hannah Arendty Gilles Deleuze. Algunos de sus artículos publicados son: "El centelleo de la infamia: los personajes de Historia universal de la infamia" (Aisthesis, núm. 59, julio de 2016, ISSN 0718-7181); "Desierto, capitalismo y valores machistas: conjunción de fuerzas feminicida en 'La parte de los crímenes' de 2666" (Cuadernos del CILHA. Centro Interdisciplinario de Literatura Hispanoamericana, Facultad de Filosofía y Letras, Universidad Nacional de Cuyo, ISSN 1852-9615); "La comunidad aporética: tensiones entre la política y lo político" (Andamios. Revista de Investigación Social, vol. 11, núm. 24, enero-abril, 2014, pp. 35-58, Universidad Autónoma de la Ciudad de México).

\section{Adso Eduardo Gutiérrez Espinoza}

(Zacatecas, 1988). Candidato a Doctor en Crítica de la Cultura y la Creación Artística (Universidad Autónoma del Estado de México). Sus líneas de investigación son: la cultura y la literatura populares en la Nueva España; edición crítica y rescate filológico de textos literarios novohispanos; la literatura menor y el esquizoanális; la sátira y el humor, y el cine desde la semiótica y la literatura 
mexicana contemporánea. Ha publicado La literatura menor desde la perspectiva deleuziana-guattariana. El caso de Diálogo estoico entre Cacolé y un Cocole bachiller (Coatepec, 2016), La reinvención mitica del Grial: Aspectos religiosos y líricos en Nunc Dimittis (UAMAzcapotzalco, 2015); sus próximas publicaciones son un capítulo del libro El color de la culpa o la confesión como revelación y acción revolucionaria y el artículo "La enfermedad como experiencia literaria en Un soplo de vida".

José Alfonso Correa

Maestro en Ciencia Política por El Colegio de México. Estudió las licenciaturas en Filosofía y Ciencias Políticas y Administración Pública en la Universidad Nacional Autónoma de México. Actualmente se desempeña como profesor de asignatura en la Facultad de Ciencias Políticas y Sociales (UnAM), y participa en diferentes proyectos de investigación en El Colegio de México y en la Facultad Latinoamericana de Ciencias Sociales-México. Sus principales áreas de interés son: los presupuestos ontológicos de la estética y sus implicaciones políticas; la relación entre elección de representantes y personalidad autoritaria; la isegoría como condición de la autonomía, y la afinidad entre el pensamiento de Marx y de Nietzsche.

\section{César Lambert Ortiz}

Licenciado en Filosofía por la Pontificia Universidad Católica de Valparaíso; doctor en Filosofía por la Albert-Ludwigs Universität Freiburg. Actualmente es académico del Instituto de Filosofía de la Pontificia Universidad Católica de Valparaíso. Líneas de investigación: fenomenología, filosofía de la religión, filosofía antigua. Recientes publicaciones: "La muerte como posible acceso a lo sagrado: perspectivas fenomenológicas" (Franciscanum, vol. LIX, núm. 168, 2017); "Sobre la experiencia de la muerte en Confesiones: 
reflexiones fenomenológicas" (Revista Philosophica, núm. 47-48, 2015); "La idea de antropocentrismo moderno en la encíclica Laudato Si" " -en conjunto con Hardy Neumann- en Jorge Mendoza (ed.), Cátedra Doctrina Social de la Iglesia (anuario 2015, PUCv); "Una aproximación a la ontología de Edith Stein" (Anales de la Facultad de Teología, núm. 104); y Cuestiones de fe y razón en Edith Stein, Agustina Serrano y Juan Francisco Pinilla (eds.) (Pontificia Universidad Católica de Chile, 2015).

\section{Yuri Guerrero Santelices}

Licenciado en Filosofía y profesor de la especialidad por la Universidad de Playa Ancha de Ciencias de la Educación; magíster en Filosofía por la Pontificia Universidad Católica de Valparaíso. Líneas de investigación: fenomenología, filosofía clásica griega. Actualmente es docente en el Instituto Profesional Santo Tomás (Viña del Mar) y ayudante académico de Griego clásico en la Universidad de Playa Ancha de Ciencias de la Educación.

\section{Carlo Del Razo Canuto}

Profesor de la licenciatura en arqueología de la Escuela Nacional de Antropología e Historia. Licenciado en Arqueología por la Escuela Nacional de Antropología e Historia (ENAH). Estudió la maestría en Humanidades en la Universidad Autónoma Metropolitana (UAM) y el doctorado en Filosofía en la Universidad de Guanajuato (UG). Como científico es especialista en prehistoria y arte rupestre del noreste de México, y en tecnologías líticas Mesoamericanas. Su trabajo filosófico es sobre los patrones de razonamiento evidencial en arqueología tales como la abducción, la inferencia a la mejor explicación y el razonamiento analógico. Actualmente está investigando el rol de la medición científica en la modelización de escalas de tiempo naturalizadas en ciencias históricas. Su trabajo más reciente fue la tesis para obtener el grado de Doctor en filosofía titu- 
lado: Medición científica en arqueología. La medición del tiempo y la historia profunda en la arqueología del Siglo XIx (2017). Sus líneas de investigación son: filosofía e historia de la ciencia, progreso cognitivo, epistemología histórica, medición científica.

\section{Luis Puelles Romero}

Profesor titular de Estética y Teoría de las Artes de la Universidad de Málaga. Ha tenido estancias de investigación en la Universidad de Amberes, en la Bibliothèque Albert I de Bruselas, en el Institut d'Esthétique et des Sciences de l'Art de la Universidad de París I (Pantheon-Sorbonne), en la Universidad Tor Vergata de Roma y en la Maison Max Ernst (Tours). Ha sido profesor invitado en la Universidad de Guanajuato (México) y en la Saint-John de New York.

Es investigador principal del Grupo de Investigación "Poéticas de la ficción en las artes de la contemporaneidad" y, junto con la profesora Maite Méndez Baiges, del Proyecto I+D Prácticas de la subjetividad en las artes contemporáneas. Es autor de, entre otros, los siguientes libros: La estética de Gaston Bachelard (Verbum, Madrid, 2002), El desorden necesario. Filosofía del objeto surrealista (Cendeac, Murcia, 2005), Lo posible. Fotografias de Paul Nougé (Cendeac, Murcia, 2007), Mirar al que mira. Teoría estética y sujeto espectador (Abada, Madrid, 2011), Honoré Daumier. La risa republicana (Abada, Madrid, 2014) e Imágenes sin mundo. Modernidad $y$ extrañamiento (2017).

Forma parte del Comité Académico del Museo Picasso Málaga y del Centro de Documentación de la Fundación Picasso de Málaga. Es asesor de colecciones de Arte y Estética de la editorial Abada (Madrid) y miembro del Comité Científico de diversas revistas nacionales e internaciones (Contrastes-Universidad de Málaga, Materiali di Estética-Università degli Studi de Milán, Testo \& senso-Università Tor Vergata de Roma, Valenciana-Universidad de 
Guanajuato, El Ornitorrinco Tachado. Revista de Estudios VisualesUniversidad Autónoma del Estado de México).

\section{Pietro Conte}

Profesor asistente de Estética en Foscari University of Venice. Después de recibir su doctorado por la Universidad de Siena en 2007, pasó dos ańo en el extranjero en un posdoctorado por la Universidad de Vasel (2007-2009). Entre los años de 2011 y 2015, trabajó como investigador asociado en la Universidad Estatal de Milan. Fue premiado con la beca por la Fundación Portuguesa para la Ciencia y Tecnología por medio del programa "Investigador FCT", gracias a la cual se le otorgó el cargo de Profesor Asistente Junior en la Universidad de Lisbon (2015-2018). Sus investigaciones se enfocan en la ilusión, el hiperrealismo, inmersión y las múltiples practicas del des-encuadre, un clúster temático que abordó priemro en el trabajo monográfico: In carne e cera. Estetica e fenomenologia dell'iperrealismo (Quodlibet, 2015). También editó las primeras traducciones italianas de Erwin Panofsky: La scultura funeraria (Einaudi, 2011), Storia del ritratto in cera (Quodlibet 2011), y La forma degli animali (Raffaello Cortina ,2013).

\section{César Moreno-Márquez}

Catedrático de Filosofía en el Departamento de Metafísica y Corrientes Actuales de la Filosofía, Ética y Filosofía Política de la Universidad de Sevilla. En la actualidad es Investigador Principal del Proyecto de Investigación (Excelencia) "Dinámicas del cuidado y lo inquietante. Figuras de lo Inquietante en el debate fenomenológico contemporáneo y las posibilidades de una orientación filosófica" (FFI2017-83770-P). Autor de los libros La intención comunicativa (1989), Tráfico de almas. Ensayo sobre el deseo de alteridad (1998), Fenomenología y filosofía existencial (2 vols., 2000) y De Mundo a Physis. Indagaciones heideggerianas (2007), así como edi- 
tor de Signo, intencionalidad, verdad. Cien años de fenomenología (2005) y Filosofía y realidad virtual (2007). Autor de numerosos artículos en publicaciones españolas y extranjeras, su área de intereses se centra en el ámbito de la fenomenología y la hermenéutica, con especial atención a problemas contemporáneos y en relación preferente a los temas de la intersubjetividad, la experiencia de lo extraño e inquietante, arte y literatura. Sus artículos más recientes son "Sobre los objetos impelentes" (Anuario filosófico, 2018), "La vida absoluta" en La razón y la vida. Escritos en homenaje a J. San Martín (2018), y "Honor vacui. Heidegger en Tindaya"(Studia Heideggeriana VII, 2018). 